\title{
LUT
}

University

\section{Investigation of a Direct Liquid Cooling System in a Permanent Magnet Synchronous Machine}

Petrov llya, Lindh Pia, Niemelä Markku, Scherman Eero, Wallmark Oskar,

Pyrhönen Juha

This is a Post-print

version of a publication

published by IEEE

in IEEE Transactions on Energy Conversion

DOI: $10.1109 /$ TEC.2019.2952431

Copyright of the original publication: (C) IEEE 2019

Please cite the publication as follows:

Petrov, I., Lindh, P., Niemelä, M., Scherman, E., Wallmark, O., Pyrhönen, J. (2019). Investigation of a Direct Liquid Cooling System in a Permanent Magnet Synchronous Machine. IEEE Transactions on Energy Conversion. DOI: 10.1109/TEC.2019.2952431

(C) 2019 IEEE. Personal use of this material is permitted. Permission from IEEE must be obtained for all other uses.

This is a parallel published version of an original publication. This version can differ from the original published article. 


\title{
Investigation of a Direct Liquid Cooling System in a Permanent Magnet Synchronous Machine
}

\author{
Ilya Petrov, Pia Lindh, Member, IEEE, Markku Niemelä, Eero Scherman, Oskar Wallmark, Senior Member, IEEE \\ and Juha Pyrhönen, Senior Member, IEEE
}

\begin{abstract}
A high demand for electrification of the transport sector has resulted in a need to provide compact and reliable electric power trains where the electric machine is a key element. The cooling system has a strong impact on the specific torque and power capability of the machine. The selection of the cooling solution should not be based on the steady-state cooling performance only but also on the transient characteristics owing to the typical operational load nature of the propulsion system, where the load is not continuous (as it usually is in industrial applications), but it frequently varies in time depending on the vehicle type and the driving style. This paper investigates in detail the cooling capabilities of a direct winding liquid cooling solution and compares it with a traditional frame liquid cooling arrangement in the transient condition. As a result of the comparison, it was found that the location of heat removal close to the heat source makes the temperature transient time faster, which allows to apply overload operating points more frequently.
\end{abstract}

Index Terms-Permanent magnet machines, Temperature measurement, Cooling, Machine windings.

\section{INTRODUCTION}

$\mathbf{S}$ INCE the first vehicle with an electric propulsion machine was released in the first half of the 19th century, the development of electric motor drives including battery and hybrid electric systems has reached a level that allows to achieve a satisfactory performance using an electric propulsion system in a vehicle. This, together with the present and forthcoming regulations concerning $\mathrm{CO}_{2}$ emissions in the transport sector, has promoted the rise of the market of full electric and hybrid electric vehicles [1].

However, the development of the electric machine used as a propulsion motor in different vehicle types (buses, passenger cars, or trucks) is still attracting significant attention [2][4]. The reason for this is the wish to achieve a compact, low-cost, high-efficiency electric machine that can provide constant power above the base speed and high torque during acceleration [5]-[7].

The proper design of an electrical traction machine is the most important element in the development of an electric motor drive system. The complete design of an electrical machine can be divided into three main subfields: electromagnetic design, thermal design, and mechanical design.

I. Petrov, P. Lindh, M. Niemelä and J. Pyrhönen are with the School of Energy Systems, Lappeenranta University of Technology, 53851 Lappeenranta, Finland.

E. Scherman is with the Saimaa University of Applied Science, 53850 Lappeenranta, Finland.

O. Wallmark is with School of Electrical Engineering and Computer Science, KTH Royal Institute of Technology, Stockholm, Sweden

Manuscript received July 3, 2019; revised August 12, 2019.
For certain applications, one or two design subfields can be more important than the others. When high torque and power densities are required, the thermal boundaries of the machine dictate the design limits, and both the electromagnetic and thermal designs should agree with these boundaries [8][10]. For example, the maximum achievable tangential stress (torque with a certain rotor radius and surface), which is proportional to the air gap flux density and the linear current density [11], are mainly limited by the maximum current density in the stator winding. Further, the maximum current density is directly linked to the possibility of the thermal design to dissipate heat from the winding [12]. Often, a high power density of an electrical machine is attempted by a high rotational speed rather than by means of a high tangential stress [13]. However, also in this case, the thermal design (along with the mechanical design) sets the maximum power and torque boundaries because of the high iron losses and, in the case of a PMSM, permanent magnet losses [14], the heat dissipation of which is equally important as dissipation of heat from the stator winding [15]. Further, in [16], it was shown that, above a certain level, the power density of an electrical machine is more effectively improved by increasing the tangential stress rather than by increasing the maximum rotational speed.

As there is a clear trend in electrical vehicle development to reduce the size and weight of electric motor drive systems [17], the thermal design often dictates the rules of the actual machine design, providing a more compact configuration when a better and more effective thermal arrangement is applied. In this paper, different thermal arrangements of a PMSM (including direct liquid cooling) are investigated and compared highlighting the conceptual difference in the heat dissipation processes, their reactions in transient conditions, and overall effectiveness. The paper is organized as follows. Section II describes the main parameters of the investigated machine and introduces different cooling arrangements applied to the machine. Section III gives some details of the thermal simulation environment and the thermal properties of the applied elements. Section IV shows the simulation results of the machine with different cooling arrangements. In Section V, the simulation results of direct liquid cooling arrangement are compared with the measured results in order to verify the overall simulation environment conditions. Section VI concludes the results. 


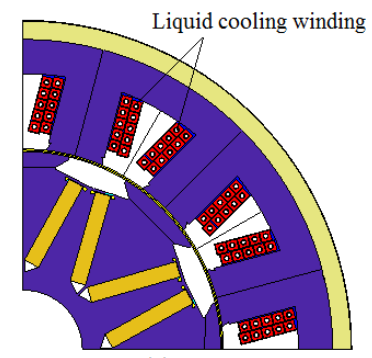

(a)

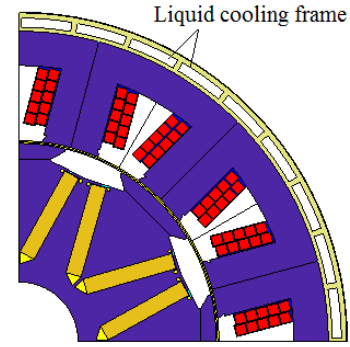

(b)
Fig. 1. Schematic view of two different liquid cooling arrangements, a) liquid cooling winding arrangement and b) liquid cooling frame arrangement.

\section{PMSM PARAMETERS AND APPLIED COOLING ARRANGEMENTS}

The electromagnetic design of the PMSM was made by following the guidelines outlined in [11], with certain boundaries related to the option of applying a winding with a direct liquid cooling arrangement, which practically did not have any adverse effect on the overall electromagnetic performance of the machine. A schematic view of the machine is shown in Fig. 1. However, the electromagnetic design is outside the scope of this paper, and an analysis of electromagnetic design solutions is not provided, while it can be found in [18].

For the sake of completeness, the main parameters (including the electromagnetic characteristics) of the machine are listed in Table I. In the case of a traction motor, both the continuous torque and the time period of the maximum applied torque (starting from cold condition) depend on the cooling effectiveness. Further, if the electromagnetic design of the machine is made by following the standard rules to achieve suitable synchronous inductance, power factor, efficiency, and peak flux density in the lamination core, there is only a limited number of options to outperform the optimum machine design and to achieve better torque capabilities. One option is to use better and more expensive materials (e.g. cobaltiron lamination, thinner lamination sheets) or to adopt a more effective cooling arrangement that is able to remove a larger amount of heat within limited time.

TABLE I

MAIN PARAMETERS OF THE DESIGNED PMSM

\begin{tabular}{lc}
\hline \hline Parameter & Value \\
\hline Nominal continuous torque $T_{\mathrm{n}}[\mathrm{Nm}]$ & 1300 \\
Nominal supply current $I_{\mathrm{ph}}[\mathrm{A}]$ & 300 \\
Maximum short period torque $T_{\max }[\mathrm{Nm}]$ & 2200 \\
Nominal speed $n_{\mathrm{N}}[\mathrm{rpm}]$ & 1500 \\
Rated voltage $U_{\mathrm{ph}}[\mathrm{V}]$ & 290 \\
Stack (physical) iron length $l_{\mathrm{Fe}}[\mathrm{mm}]$ & 200 \\
Stator inner diameter $D_{\mathrm{s}}[\mathrm{mm}]$ & 304 \\
Stator outer diameter $D_{\mathrm{se}}[\mathrm{mm}]$ & 470 \\
Rotor outer diameter $D_{\mathrm{r}}[\mathrm{mm}]$ & 300 \\
\hline \hline
\end{tabular}

In this paper, two essentially different cooling arrangements are introduced and shown in Fig. 1. The key difference in these two systems is the positioning of the heat removal. For instance, in Fig. 1 (a), the heat removal is located directly in the winding, whereas in Fig. 1 (b), the heat removal is located in the stator frame. The system having the heat removal
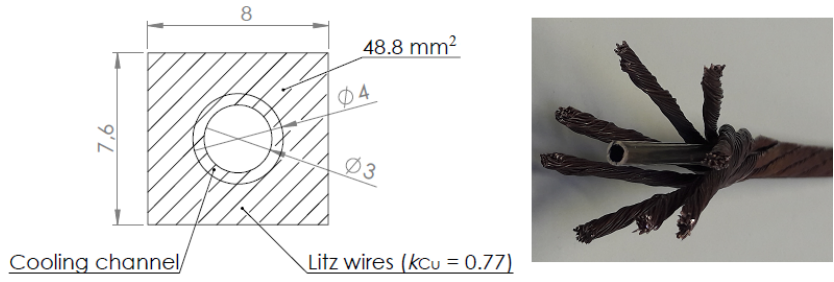

Fig. 2. Schematic view of the wire used in the DWLCA and photograph of DWLCA containing eight wire bundles wrapped around the stainless steel tube, where each bundle contains 24 twisted strands.

directly in the stator winding constitutes the direct winding liquid cooling arrangement, which, throughout the paper, is referred to as DWLCA. In the paper, the more conventional liquid cooling in the housing is referred to as the frame liquid cooling arrangement (FLCA). The applicability of DWLCA in relatively low power electric vehicle motors is investigated in [19], [20] covering more practical details.

The FLCA is well known and widely used by applying a water jacket in the frame of the machine to remove the heat. However, for the sake of completeness, a brief introduction is given to the DWLCA; a more detailed description can be found in [21], [22]. The main idea is to combine a stainless steel tube with a Litz winding evenly distributed around it as shown in Fig. 2. This allows arranging direct liquid cooling inside the winding. Applying Litz winding in the coil helps to avoid excessive eddy currents and circulating currents in the winding, especially at higher electric frequency which in the case of studied machine can be up to $380 \mathrm{~Hz}$ [18], whereas the stainless steel tube in the middle does not produce any significant eddy current losses itself in the studied motor [21]. The disadvantage of this approach is that it reduces the flexibility of the armature winding and makes the winding work somewhat more demanding than traditionally. However, by selecting a correct geometry and suitable dimensions for the tube, the work can be carried out successfully. Still, it is advisable to use a simple winding structure, such as a fractional slot concentrated nonoverlapping winding [23], which does not have an overlapping end winding, and each coil is wound around only one armature tooth.

\section{Simulation ENVIRONMENT AND THERMAL PROPERTIES OF THE PMSM ELEMENTS}

\section{A. Selection of the simulation environment}

There are different approaches and different simulation environments for the estimation of the thermal performance of electrical machines. One of the simplest simulation methods is the analytic approach combined with lumped-parameter models [24]. It requires relative positions of the active machine elements along with their thermal conductivities, loss values, and the heat transfer coefficients of the heat removal elements (e.g., frame surface or water jacket). Usually, for a rough estimation of the average temperature over a certain machine element (e.g. stator core or winding), this approach will suffice. However, it may not reveal some local overheated regions. 


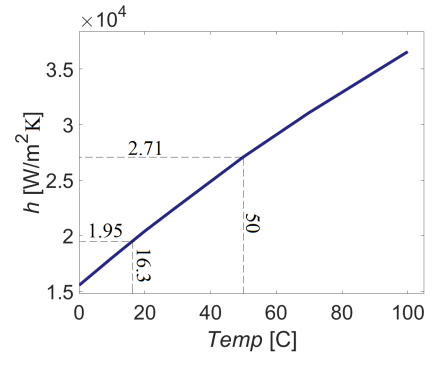

Fig. 3. Estimated heat transfer coefficient (as a function of water temperature) found by standard analytical approach for water circulating in a tube with flow velocity of $4.6 \mathrm{~m} / \mathrm{s}$ [25].

Another approach is the Finite Element Method (FEM), which takes into account the complex geometry of the machine providing an opportunity to investigate the temperature distribution within a particular element (e.g., winding coil or PM). The parameters needed for these simulations are, in principle, the same as in a lumped model in addition to the actual detailed geometrical dimensions. However, this method can be considered more precise, because it takes into account a complex machine geometry in the simulation.

The third potential approach of thermal simulation is Computational Fluid Dynamics (CFD). The main advantage of this approach is the opportunity to estimate the heat transfer coefficient based on the cooling arrangement parameters (such as flow rate, liquid, or gas properties), without having to rely on empirical models or actual measurements of these parameters [21]. The CFD simulation is heaviest in terms of computational resources.

In principle, FEM and CFD are different techniques to simulate solid structures and liquids/gases, respectively. These methods are complement each other but cannot replace each other since they are in general for different targets. In this paper, thermal properties of the coil (e.g. heat transfer coefficient) were obtained in advance by analytical computations with the following thermal measurements. This allowed to use the direct water-cooled coil straight in the simulation model. The measurements applied in thermal analysis can be regarded as experiment-in-loop system where the estimated results are used in FEM model. This allowed to avoid using the CFD analysis (which inherently involves certain assumptions and causes extra uncertainty), and it was decided to use 2D and 3D FEM simulation environments for the final machine models by assigning the boundary condition of the surfaces that have a direct contact with cooling liquid with the found heat transfer coefficient along with the temperature of the cooling water.

\section{B. Evaluation of the DWLCA cooling characteristics}

By using the Reynolds number, Prandtl number and Nusselt number [25] the heat transfer coefficient $h_{\mathrm{c}}$ for turbulent water flow in a tube can be estimated analytically. The temperature, flow speed and pressure of the water must be known. The result of analytical calculation is shown in Fig. 3. The heat transfer coefficient found by this approach is verified by measurements as follows.

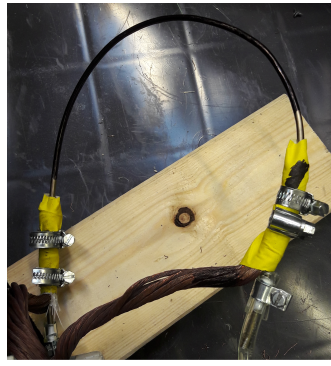

(a)

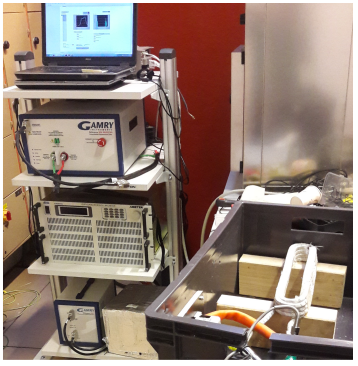

(b)
Fig. 4. a) Stainless steel tube covered with a thin layer of black color (for better temperature measurements by an infrared camera) with a total length of $450 \mathrm{~mm}$. The current is supplied through the connectors to the tube to generate power losses in it. The water is circulating in the tube at a flow rate of $21 / \mathrm{min}$. The inlet and outlet water temperatures are measured by PT -100 sensors, b) coil measurement test setup. The coil contains eight turns in total having a similar overall coil shape as in the actual motor. The total coil length is $5.1 \mathrm{~m}$. The current is supplied through the connectors of the coil to generate power losses in it. The water is circulating in the inner tube at a flow rate of $21 /$ min having a pressure 6 bar. The inlet and outlet water temperatures are measured by PT-100 sensors.

The procedure of coil measurements was divided into two parts. First, the stainless steel tube was tested alone (without copper strands wrapped around it), having the total resistance 0.05 Ohm. Fig. 4 (a) shows the test arrangement of the first test procedure. The main objective of this measurement was to identify the actual heat transfer coefficient between the water and the steel tube wall. In order to avoid any possible heat transfer to the environment and ensure that all the heat generated in the tube is dissipated through the water, it was decided to operate with a temperature on the outer surface of the tube equal to the surrounding air temperature.

Considering that the surface temperature of the tube has to be equal to the temperature of the environment, the inlet water temperature has to be lower than the environment temperature when current is supplied to the tube (which generates heat loss in it). For example, if the power loss generated in the tube is equal to $370 \mathrm{~W}$, the inlet water temperature has to be equal to $15^{\circ} \mathrm{C}$ to keep the surface temperature of the tube the same as the ambient temperature (e.g. $22.3^{\circ} \mathrm{C}$ ). The correctness of the surface temperature was verified using an infrared camera, Fluke Ti10. Fig. 5 (a) shows the surface temperature of the tube measured by the infrared camera when the generated loss in the tube is $370 \mathrm{~W}$ and the inlet water temperature is $15^{\circ} \mathrm{C}$. The precision of the infrared camera was verified with the same tube at no load but applying different water temperatures. For example, Figs. 5 (b), (c), and (d) show the tube temperature when the water temperature is $22.3^{\circ} \mathrm{C}, 21.8^{\circ} \mathrm{C}$ and $22.8^{\circ} \mathrm{C}$ respectively. It can be clearly seen that when the water temperature is close to the ambient temperature, it has almost the same color as the background, whereas if the temperature of the tube is below the environment temperature, the tube color is "colder", Fig. 5 (c), and when the temperature of the water and the tube is above the environment temperature, its color is "warmer", Fig. 5 (d). Therefore, it could be concluded that the precision of the infrared camera is at least within $\pm 0.5^{\circ} \mathrm{C}$.

The tube temperature was measured applying different heat 


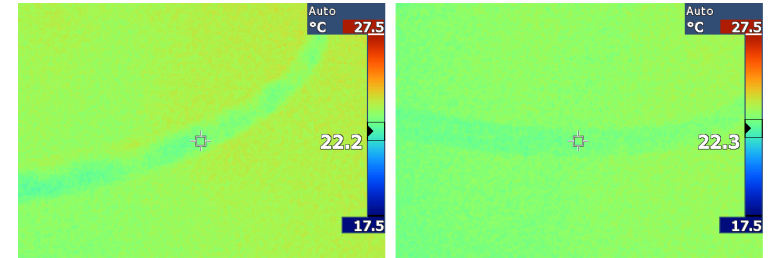

(a)

(b)

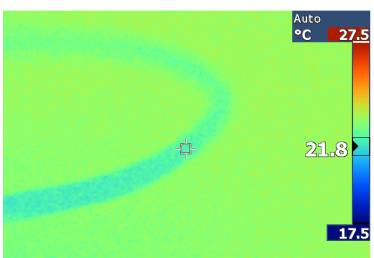

(c)

(d)

Fig. 5. a) Thermal image with a water temperature of $15^{\circ} \mathrm{C}$ and $370 \mathrm{~W}$ losses in the tube, b) thermal image with a water temperature of $22.3^{\circ} \mathrm{C}$ and no losses, c) thermal image with a water temperature of $21.8^{\circ} \mathrm{C}$ and no losses, and d) thermal image with a water temperature of $22.8^{\circ} \mathrm{C}$ and no losses.

power values. At the same time, the inlet water temperature was adjusted to keep the tube surface temperature the same as the ambient temperature. The set of applied heat power values included $370 \mathrm{~W}, 190 \mathrm{~W}$, and $100 \mathrm{~W}$, (by applying DC current $86 \mathrm{~A}, 61.6 \mathrm{~A}$ and $44.7 \mathrm{~A}$ respectively) and the inlet water temperature at these heat power values (keeping the surface tube temperature the same) was adjusted to be $15^{\circ} \mathrm{C}, 18.5^{\circ} \mathrm{C}$, and $20.3^{\circ} \mathrm{C}$ respectively. However, obviously, because of the heat flow from the tube to the water circulating in it, the temperature of the outlet water temperature was higher than the inlet water temperature. For example, the outlet temperature in the case of $370 \mathrm{~W}$ was $17.6^{\circ} \mathrm{C}$, in the case of $190 \mathrm{~W}$ it was $19.9^{\circ} \mathrm{C}$, and in the case of $100 \mathrm{~W}$ it was $21^{\circ} \mathrm{C}$. Therefore, the temperature of the tube was measured in the middle of the tube, and it was assumed that the temperature of the water in this region is an average of the inlet and outlet temperatures, which are $16.3^{\circ} \mathrm{C}, 19.2^{\circ} \mathrm{C}$, and $20.65^{\circ} \mathrm{C}$ for $370 \mathrm{~W}, 190 \mathrm{~W}$, and $100 \mathrm{~W}$ respectively. This water temperature is regarded as the temperature of the region to which the heat flux is conducting $T_{1}$ (overall temperature of the cooling liquid).

The heat transfer coefficient $h_{\mathrm{c}}$ can be estimated as

$$
h_{\mathrm{c}}=\frac{Q}{S\left(T_{2}-T_{1}\right)},
$$

where $Q$ is the total generated heat power [W], $S$ is the area through which the heat flux is dissipated $\left[\mathrm{m}^{2}\right], T_{2}$ is the temperature of the region from which the heat flux is conducting (temperature in the inner surface of the tube). The temperature in the inner surface region of the tube was found using experiment-in-loop approach and described hereafter.

Assuming that the temperature in the outer surface of the steel tube is the same as in the inner surface of the tube (because of the relatively thin tube wall), it is possible to estimate the heat transfer coefficient if the water temperature, the tube surface temperature, the surface area, and the heat
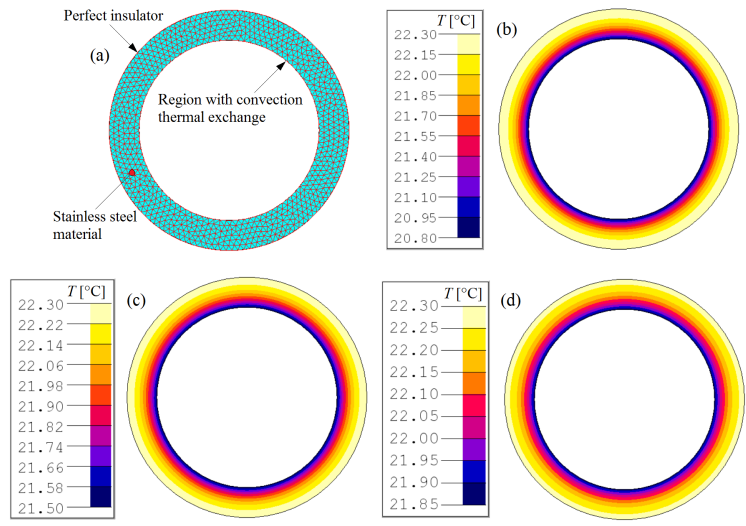

Fig. 6. a) 2D FEM model of the tube having the same dimensions as the measured tube, b) temperature distribution within the tube having $370 \mathrm{~W}$ of losses in the tube, a water temperature of $16.3^{\circ} \mathrm{C}$, and a heat transfer coefficient of convection (between the inner tube surface and water) of $\left.19300 \mathrm{~W} / \mathrm{m}^{2} \mathrm{~K}, \mathrm{c}\right)$ temperature distribution within the tube having $190 \mathrm{~W}$ of losses in the tube, a water temperature of $19.2^{\circ} \mathrm{C}$, and a heat transfer coefficient of convection of $19300 \mathrm{~W} / \mathrm{m}^{2} \mathrm{~K}$, d) temperature distribution within the tube having $100 \mathrm{~W}$ of losses in the tube, a water temperature of $20.65^{\circ} \mathrm{C}$, and a heat transfer coefficient of convection of $19300 \mathrm{~W} / \mathrm{m}^{2} \mathrm{~K}$.

power values are known. However, this assumption is not accurate; even though the steel tube wall is quite thin $(0.5 \mathrm{~mm})$, there is still a temperature gradient from the inner tube radius towards the outer tube radius. This gradient can be estimated by a 2D FEM analysis of this tube, as it is shown in Fig. 6 . In this figure, a 2D model of the tube is presented. The outer surface of the tube in the model is considered a perfect thermal insulator that does not conduct any heat. The inner surface of the tube has thermal exchange by convection with an adjusted heat transfer coefficient of the convection. The main body of the tube is stainless steel with a thermal conductivity of $14.4 \mathrm{~W} / \mathrm{mK}$ (stainless steel with grade 304 ).

The heat transfer coefficient of convection was adjusted in the model to achieve the actual ambient temperature at which the tube was tested. The heat transfer coefficient in the 2D FEM model was adjusted until the resulting surface tube temperature was found to be the same as the value obtained during the measurements. For example, in the model of the tube, Fig. 6 (a), the same power loss and water temperature were applied as during the measurements $\left(370 \mathrm{~W}, 16.3^{\circ} \mathrm{C}\right)$ and the heat transfer coefficient in the model was adjusted until the surface tube temperature reached $22.3^{\circ}$ C, Fig. 6 (b). Then, the resultant heat transfer coefficient in the 2D FEM was verified with other measurement conditions $(190 \mathrm{~W}$ power loss with a $19.2^{\circ} \mathrm{C}$ water temperature and $100 \mathrm{~W}$ power loss with a $20.65^{\circ} \mathrm{C}$ water temperature), which gave almost the same surface tube temperature (within $0.05^{\circ} \mathrm{C}$ difference) that was achieved during the measurements $\left(22.3^{\circ} \mathrm{C}\right)$ as can be seen in Figs. 6 (c) and (d). The heat transfer coefficient of convection that was obtained during this adjustment procedure is $h_{\mathrm{c}}=19300 \mathrm{~W} / \mathrm{m}^{2} \mathrm{~K}$. Otherwise, assuming that the inner steel surface (which is in contact with water) had the same temperature as the outer surface of the tube, the heat transfer coefficient could be estimated directly by using (1), and it would be equal to $h_{\mathrm{c}}=14300 \mathrm{~W} / \mathrm{m}^{2} \mathrm{~K}$, which is only $74 \%$ 


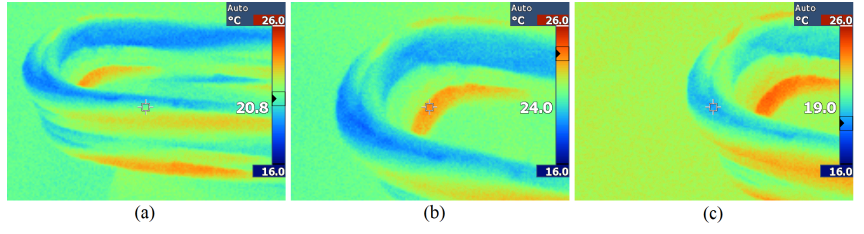

Fig. 7. Thermal image with a supply power of $135 \mathrm{~W}$, a water flow of $21 / \mathrm{min}$, an inlet water temperature of $15^{\circ} \mathrm{C}$, and an outlet water temperature of $16^{\circ} \mathrm{C}$, the average water temperature in the coil being $15.5^{\circ} \mathrm{C}$. a) Overall illustration of the winding; b) the hottest winding region $\left(24^{\circ} \mathrm{C}\right)$; $\mathrm{c}$ ) the coldest winding region $\left(19^{\circ} \mathrm{C}\right)$

of the result obtained by using the 2D FEM model. Comparing the measured heat transfer coefficient $\left(19300 \mathrm{~W} / \mathrm{m}^{2} \mathrm{~K}\right.$ at water temperature $16.3^{\circ} \mathrm{C}$ ) with the analytical results $\left(19500 \mathrm{~W} / \mathrm{m}^{2} \mathrm{~K}\right.$ at the same temperature, Fig. 3) it could be concluded that the analytical approach results in accessible precision and can be further used for other water temperatures (e.g. $h_{\mathrm{c}}=27100 \mathrm{~W} / \mathrm{m}^{2} \mathrm{~K}$ at $50^{\circ} \mathrm{C}$ ). However, it should be noted that a particular deviation of the estimated heat transfer coefficient from the actual one would not lead to a high difference in the overall thermal solution results, because the temperature gradient at the surface of the tube, which in contact with the cooling water, is relatively small compared with the temperature gradients in other regions of the system (e.g. over tube wall or air gap layers).

The next measurement step (when the tube cooling parameters are known) is the measurement of the whole coil. Fig. 4 (b) shows the test bench of the coil measurement, which is, in principle, the same as the test setup of the cooling tube alone. The measurement procedure is also similar to the one applied to the steel tube. A particular current (173 ADC) was applied to the coil to generate the heat power in it (135 W). The value of the generated heat power was selected in a way that with the minimum available water input temperature $\left(15^{\circ} \mathrm{C}\right)$ the coil surface temperature is the same as the ambient temperature to minimize the heat dissipation from the coil to the environment. However, as can be seen in Fig. 7 (a), the coil did not have a uniform temperature distribution during the test, but there was some temperature variation within the coil surface. For example, at the power of $135 \mathrm{~W}$, the inlet temperature of $15^{\circ} \mathrm{C}$, the outlet temperature of $16^{\circ} \mathrm{C}$, the water flow of $2 \mathrm{l} / \mathrm{min}$, and the ambient temperature of $21.5^{\circ} \mathrm{C}$, the hottest spot in the coil was $24^{\circ} \mathrm{C}$, Fig. 7 (b), and the coldest region was $19^{\circ} \mathrm{C}$, Fig. 7 (c). The reason for such a variation can be explained by the uneven thermal connection from the tube to different wire bundles wrapped around it along the coil length. The uneven thermal connection is caused by different degrees of tension caused by the curvature form of the coil and manual handling of the winding when being wound to form the coil.

In order to estimate the thermal connection between the wire bundles wrapped around the steel tube, a 3D FEM model of the coil was prepared as shown in Fig. 8. The model has 729010 volume elements and 229025 nodes. The coil in the model contains a steel tube inside the winding similarly as in the actual coil. The inside surface of the tube has the same heat transfer coefficient setting as obtained by the previously described procedure $\left(h_{\mathrm{c}}=19300 \mathrm{~W} / \mathrm{m}^{2} \mathrm{~K}\right)$. The temperature of the fluid that is in contact with the inner tube surface in the model was set the same as it is in the measured coil $\left(15.5^{\circ} \mathrm{C}\right.$ ). The conductivity of the copper region (square region that surrounds the steel tube) was set equal to the copper conductivity ( $k=400 \mathrm{~W} / \mathrm{mK})$. However, in reality, this copper conductivity is only valid along the wound path of the coil, whereas owing to a certain distance between each single strand, the overall thermal conductivity of the copper region is significantly reduced in the radial direction. Again, this overall thermal conductivity in the radial direction in the copper region is a result of the degree of tension applied to the wire. Therefore, it was decided to set the thermal conductivity of the copper region in the model as it were made of a solid piece, which allows to concentrate the degree of the tension parameter of the copper wrapped around the steel tube only in one place, in this case, in an extra air gap between the steel tube and the copper region that surrounds this steel tube. It was found that the surface of the coil in the model reaches the hottest measured temperature (applying the same heat power) when the air gap between the copper and the steel is $0.103 \mathrm{~mm}$, Fig. 8 (a), and it reaches the coldest measured temperature when the air gap is $0.04 \mathrm{~mm}$, Fig. 8 (b). Thus, it can be assumed that the overall average degree of tension of the copper wrapped around the steel tube can be represented in the model as an extra air gap between the copper and the steel tube, equal to $0.0715 \mathrm{~mm}$. Alternative approach to varying the air gap between the copper and the steel tube is using equivalent thermal conductivity on cross-plane to the flow direction, which could achieve similar results or simply use the analytical approach. However, the approach with the equivalent air gap between the copper and the tube might be closer to the real phenomenon that occurs in the coil (actual reason of different measured temperature distribution on the winding surface). Additionally, the found air gap values can give a preliminary insight of the actual equivalent air gap between the copper strands surfaces and the tube outer surface. The FEM computation environment was selected for the heat transfer simulation instead of the analytical approach because the same FEM model was applied in the electromagnetic modeling. Only the solver changes while the geometrical model remains the same. Despite being convenient this also helps avoiding any potential errors caused by the transformation of the results from one computation environment to another one. The reason of applying FEM in the next computation steps is the presence of rotor and stator cores, stator frame and an impregnation layer in the winding. In this case, the position of each winding turn within the stator slot and the overall thickness of the impregnation layer would affect the overall picture of the temperature distribution. Such a thermal network structure is easier to be implemented in FEM which provides more precise results rather than using an analytical approach.

\section{TRANSIENT Simulation RESUlts OF THE MACHINES WITH DIFFERENT COOLING ARRANGEMENTS}

Because of the large number of steps required during the transient simulation, it is not time efficient to evaluate a 


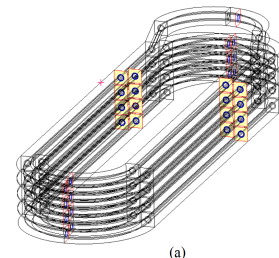

(a)

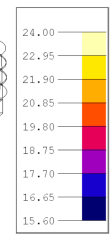

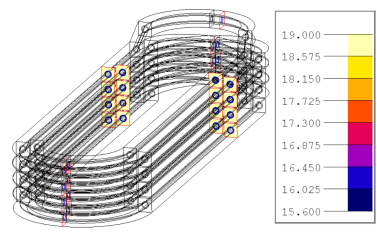

Fig. 8. Temperature distribution in the wires along the coil cut with $135 \mathrm{~W}$ of power loss in the coil, the heat transfer coefficient in the inner steel tube surface $h_{\mathrm{c}}=19300 \mathrm{~W} / \mathrm{m}^{2} \mathrm{~K}$, a perfect insulator in the outer wire surface, a) with a $0.103 \mathrm{~mm}$ gap between the steel tube and the copper, and b) with a $0.04 \mathrm{~mm}$ gap between the steel tube and the copper. The temperature is shown only along the coil cut (not on the coil surface) because in the model the whole outer surface of the coil has approximately the same temperature.

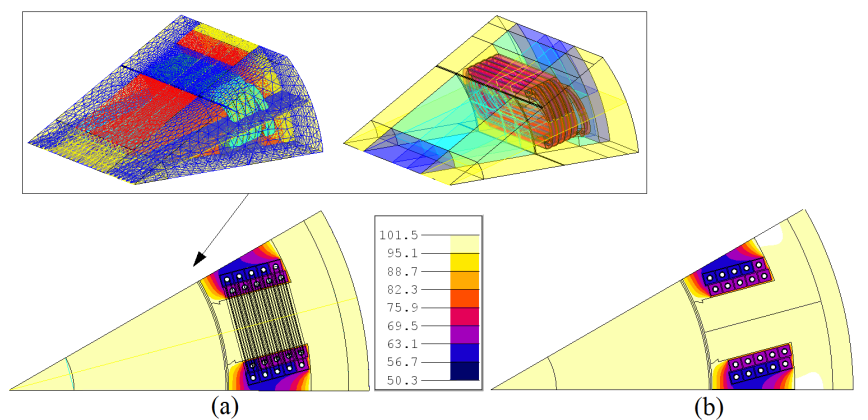

Fig. 9. Temperature distribution in the middle cut of the 3D FEM model (a) and in the 2D FEM model. Losses in the 3D model are the following: $320 \mathrm{~W}$ in the coil and $1200 \mathrm{~W}$ in the whole core. The loss in the coil in the 2D FEM model is reduced by $38.5 \%$, which is equal to the end winding proportion of the total winding length of the coil. The parameters of the models are following: distance between adjacent windings is $0.7 \mathrm{~mm}$, a natural thermal convection of the steel frame to the air of $10.6 \mathrm{~W} / \mathrm{m}^{2} \mathrm{~K}$, an emissivity coefficient of the steel frame of 0.075 , the distance between the winding and stator core is $1 \mathrm{~mm}$, the temperature of the cooling liquid is $50^{\circ} \mathrm{C}$, the air surrounds the end windings from both ends of $3 \mathrm{D}$ model.

transient simulation in 3D FEM, especially considering the extra computation iterations for the proper adjustment of the winding position within the stator slot along with the adjustment of the impregnation layer thicknesses. Therefore, a 2D FEM model was adopted for transient simulations. In this case, the total winding loss in the $2 \mathrm{D}$ model was adjusted to get the same temperature distribution shown in Fig. 9 (b) as it is in the 3D model shown in Fig. 9 (a). The winding loss in the $2 \mathrm{D}$ model was reduced by $38.5 \%$ compared with the $3 \mathrm{D}$ model, which equals the proportion of the end winding length of the total winding length.

A schematic view of the thermal models used in the transient simulations is shown in Fig. 10. Owing to the symmetry of the machine, only one-twelfth of it was simulated, with 10966 first-order elements and 22413 nodes. The machine version with another cooling arrangement (liquid cooling in the frame instead of liquid cooling in the winding) has similar thermal properties of the elements except for the absence of liquid cooling in the stator winding and the presence of liquid cooling in the stator frame with the same heat transfer coefficient $\left(h_{\mathrm{c}}=27100 \mathrm{~W} / \mathrm{m}^{2} \mathrm{~K}\right)$, Fig. 10 (b). Of course, the heat transfer coefficient of the stator frame cannot be exactly the same as it is in the stator winding, but it was decided to

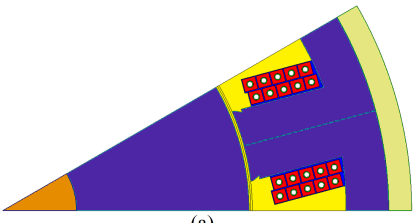

(a)

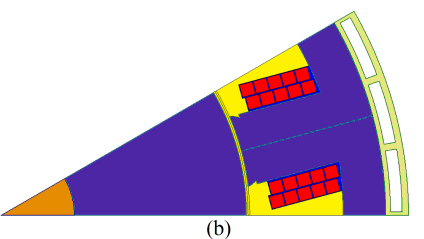

Fig. 10. 2D FEM model of the machine with a) DWLCA and b) FLCA. The total surface cooling area in the model with DWLCA is $0.0251 \mathrm{~m}^{2}$ and it is in the model with FLCA is $0.054 \mathrm{~m}^{2}$. The total cooling path length in the model with DWLCA is $4 \mathrm{~m}$ and it is in the model with FLCA is $0.6 \mathrm{~m}$. The liquid cooling surface in both models is assigned to have heat transfer coefficient $h_{\mathrm{c}}=27100 \mathrm{~W} / \mathrm{m}^{2} \mathrm{~K}$.

make it the same for more fair comparison of two different positions of the water liquid cooling (in stator winding and in stator frame) keeping the effectiveness of the cooling the same.

Even though a detailed analysis of the a separate coil used in the motor was prepared, there is still a large number of unknown parameters such as the exact position of the winding within the slot (which affects the heat transfer between the stator core and the winding), the thermal connection between the stator stack and the outer frame, the amount of the impregnated material that penetrates into the coil and surrounds it, and the distance between neighboring wires. Taking the model shown in Fig. 10 (a) as a reference, some of its parameters can be adjusted by the trial and error method to match the steady-state performance of the actual machine. These parameters were: a total insulation and impregnation layer (surrounding the winding) of $0.5 \mathrm{~mm}$, a natural thermal convection of the steel frame to the air of $10.6 \mathrm{~W} / \mathrm{m}^{2} \mathrm{~K}$, an emissivity coefficient of the steel frame of 0.075 , a distance between the neighboring wires of $0.7 \mathrm{~mm}$, and a slot insulation thickness of $1 \mathrm{~mm}$.

A typical thermal condition in an electric motor drive applied as a propulsion system is not a steady-state but a transient one because of the frequent acceleration and deceleration modes and not ideally flat roads with certain slopes. Therefore, it is important to observe how well the thermal management of the machine handles heavy-duty cycles and recovers the temperature of the machine back to a condition ready for the following overload operations. A short recovery time also contributes to a possible reduction in the size and weight of the machine as it allows to apply more frequent overload modes.

An example of applying high power for a short period of time during relatively low-power operation in both machines with the DWLCA and the FLCA is shown in Fig. 11 (a). It should be noted that the stator winding losses in the machine with the FLCA are inherently lower than in the machine with the DWLCA because of a larger copper conducting area when no stainless steel tube is applied inside the winding. In this case, the tube occupies $\pi r^{2}=4 \pi=12.6 \mathrm{~mm}^{2}$, whereas the total copper area in the liquid cooling winding (having a copper space factor $k_{\mathrm{Cu}}=0.77$ ) is $37.1 \mathrm{~mm}^{2}$, which means that the traditional Litz winding without a stainless steel tube would have $37.1 \mathrm{~mm}^{2} /\left(37.1 \mathrm{~mm}^{2}+0.77 \times 12.6 \mathrm{~mm}^{2}\right) \times$ $100 \%=79 \%$ of Joule losses compared with the DWLCA. The overall length of the winding remains the same in both machines. The total phase resistance (comprising four coils 


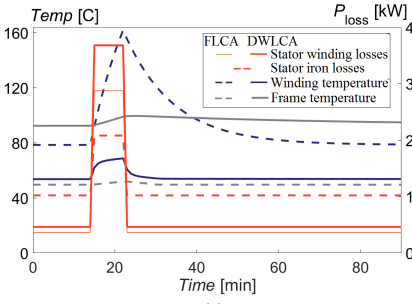

(a)

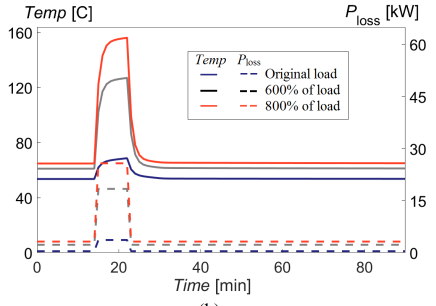

(b)
Fig. 11. a) Temperature in the stator winding and the stator frame of a machine with the DWLCA and a machine with the FLCA, applying high torque for a short time during low-power operation. b) Temperature in the stator winding and the stator frame of a machine with the DWLCA, applying a high load for a short time (nominal, $600 \%$ of nominal and $800 \%$ of nominal) during low-power operation. 2D FEM.

in series) in the machine with DWLCA is $0.0142 \mathrm{Ohm}$ at $20^{\circ} \mathrm{C}$, and the total resistance in the machine with FLCA is $0.0112 \mathrm{Ohm}$ at $20^{\circ} \mathrm{C}$. Fig. 11 (a) shows that despite having higher copper losses, the machine with the DWLCA has a much lower temperature in the winding than the machine with the FLCA. This is an obvious result as the cooling in DWLCA is realised directly in the winding. However, what is more important here is the time it takes to reduce the winding temperature after application of high power. Considering the machine with the FLCA, it takes 8 min to reduce the temperature rise caused by the high-power mode to a half of this rise, whereas the machine with the DWLCA only needs 1 min.

The relative recovery time is not related to the total maximum temperature reached during the high-power mode. This can be explained considering (1). Based on (1), the heat flux depends on the heat transfer coefficient and the temperature difference between the regions where the heat flux is flowing (cooling liquid and tube wall). Therefore, a higher temperature difference leads to a higher heat flux, which makes the relative recovery time (e.g., to halve the temperature rise caused the high-power mode in the winding) basically the same considering any short period load. This can also be seen in Fig. 11 (b) which shows the temperature transient in a machine with the DWLCA, applying higher power loss in the stator winding.

A comparison of the temperature transient in Fig. 11 (b) with the temperature transient in the machine with the FLCA depicted in Fig. 11 (a) shows that even with the similar peak temperature the relative recovery time in the machine with the DWLCA is much shorter. This can be explained by considering the whole heat transfer path from the source of losses to the heat removal region, which includes internal elements. These elements, in terms of thermal management, are represented by thermal conductivity and total distance through which the heat flux passes. The heat flux can now be expressed as

$$
q=\frac{\lambda}{l}\left(T_{2}-T_{1}\right)
$$

where $\lambda$ is the thermal conductivity of the material $[\mathrm{W} / \mathrm{mK}]$, and $l$ is the distance of heat flux flow in the material.

When the heat removal is located directly in the heat source region similarly to the DWLCA, it improves (additionally
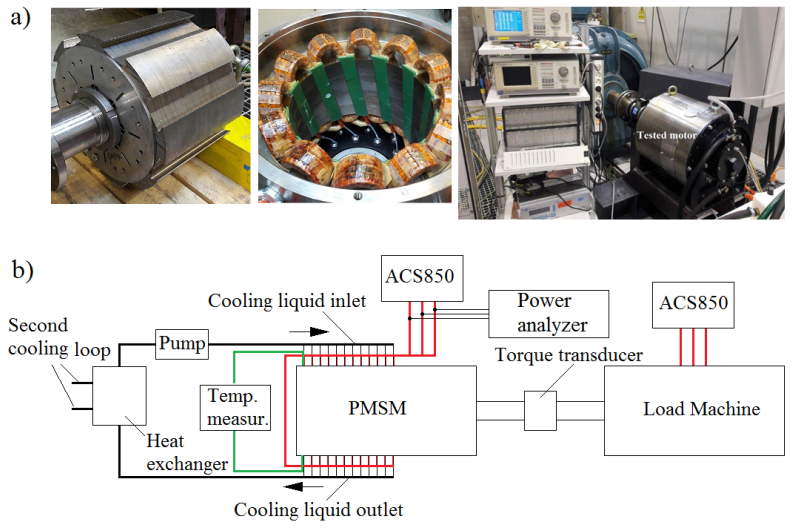

Fig. 12. a) Rotor, stator, and test bench and b) schematic view of the test bench.

to the steady-state cooling effectiveness) the heat transfer in transient conditions, especially if the heat source has a relatively low heat capacity. The elements with a high heat capacity, such as the stator core (including housing), are not very susceptible to short time periods of high heat generation. Fig. 11 (a) shows that the frame temperature in the machine with the DWLCA is relatively high, but it does not increase as rapidly as the stator winding temperature because of the high heat capacity. Thus, it can be concluded that when considering a transient condition it is more important to apply the DWLCA rather than the FLCA. First of all, the winding is inherently more isolated from the environment, having different types of low thermal conductivity insulation layers (e.g. slot insulation and varnishing impregnation) and thus, poor heat transfer capabilities from the winding. Secondly, the winding typically has a lower heat capacity than the stator core (including housing), which makes it more vulnerable to transient temperature variations at different power losses. In addition, in a vehicle, the torque variation (pushing the power pedal) is typically more frequent than the speed variation (actual vehicle speed), whereas torque is directly related to the supply current and, consequently, to winding losses.

\section{Measurements And Verification of the Model}

The machine with the DWLCA having the same geometry shown in Fig. 1 and properties listed in Table I was assembled. The rotor and the stator are shown in Fig. 12 (a) together with the test bench. A schematic view of the test bench is shown in Fig. 12 (b). First, losses and efficiency as a function of torque and rotational speed were measured for the speed range from $300 \mathrm{rpm}$ to $1200 \mathrm{rpm}$ at intervals of $150 \mathrm{rpm}$, and the torque range from $130 \mathrm{Nm}$ to $1300 \mathrm{Nm}$ at intervals of $130 \mathrm{Nm}$. However, the measured losses had some mismatch with the estimated losses at higher powers. It is assumed that most of these extra losses are caused by the pulse-width-modulation control inducing extra eddy-current and hysteresis losses in the lamination core [26]. The rotor and stator core material used in the motor is M350-50A. Therefore, the estimated losses were corrected based on the measured results by adding extra losses to the estimated stator iron loss component. The estimated (corrected) losses and the estimated efficiency together with 


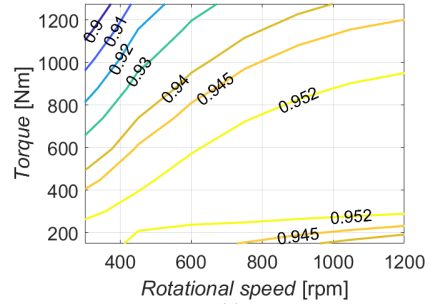

(a)

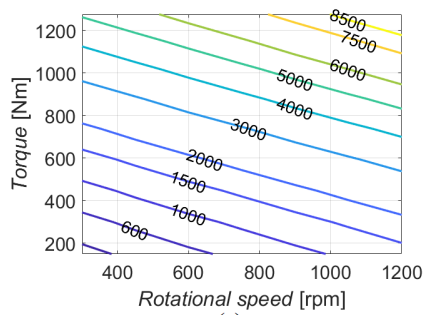

(c)

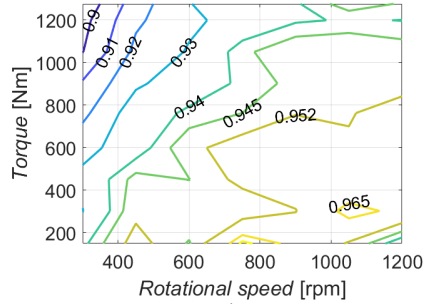

(b)

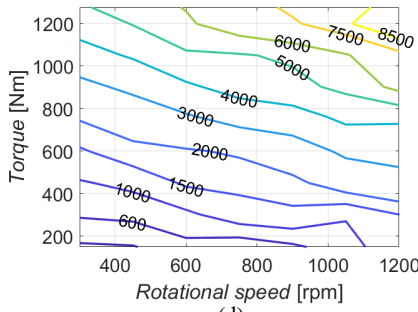

(d)

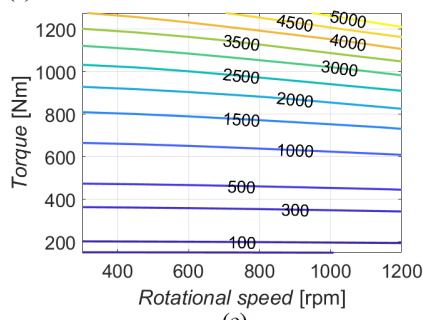

(e)

Fig. 13. a) Estimated efficiency, b) measured efficiency, c) estimated losses, d) measured losses and e) estimated losses in the stator winding.

the measured losses and the measured efficiency are shown in Fig. 13.

One step of the measurement procedure was the evaluation of the steady-state temperature under a certain load (600 rpm, $460 \mathrm{Nm}$ ), then applying nominal torque, keeping the same speed $(600 \mathrm{rpm}, 1300 \mathrm{Nm})$ for nine minutes, and then switching back to the low load (600 rpm, $460 \mathrm{Nm}$ ). In these load conditions, the temperature in the stator slots (of different winding phases) and the temperature in the frame were measured, representing the transient temperature. Fig. 14 shows the measured and estimated temperatures during the described load variations. First, it can be seen that the measured temperatures in the three phases are significantly different. It can be explained by the random relative positions of the sensors in the slots and other uncertain factors such as liquid water flow in different coils and winding positions relative to the stator core. However, in general, the estimated transient temperature is quite close to the average measured temperature values, except for the very beginning of transients where the estimated temperature in the slot reacts faster. The reason for this could be an extra delay caused by heating of the actual sensor located between the winding turns compared with the virtual sensor in the model that immediately follows the simulated temperature.

The next measurement and estimation of the transient temperatures was performed applying different speed and torque values. The speed starts from $1200 \mathrm{rpm}$ and the torque starts from $1300 \mathrm{Nm}$ with a gradual reduction to $150 \mathrm{Nm}$. When the torque reaches $150 \mathrm{Nm}$, the speed is reduced to 1050

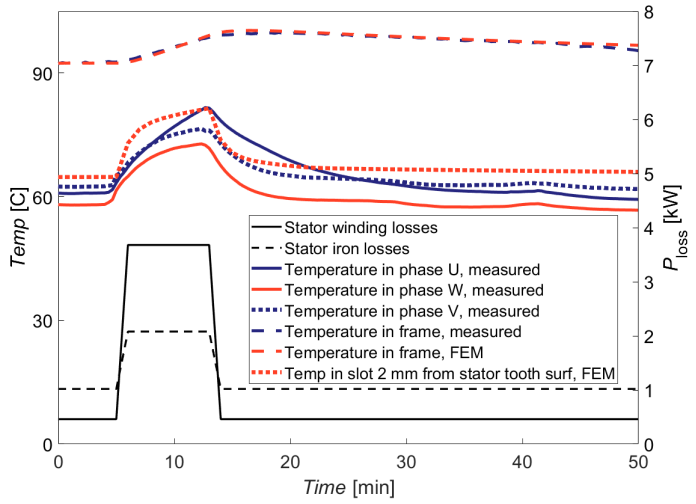

Fig. 14. Measured transient temperature in the slots of three different phases and in the frame, and estimated temperature in the slot winding and the frame applying load variation. Water inlet temperature is $50^{\circ} \mathrm{C}$. Water outlet temperature was close to the water inlet temperature along the whole transient (with small variations within $2^{\circ} \mathrm{C}$ ).

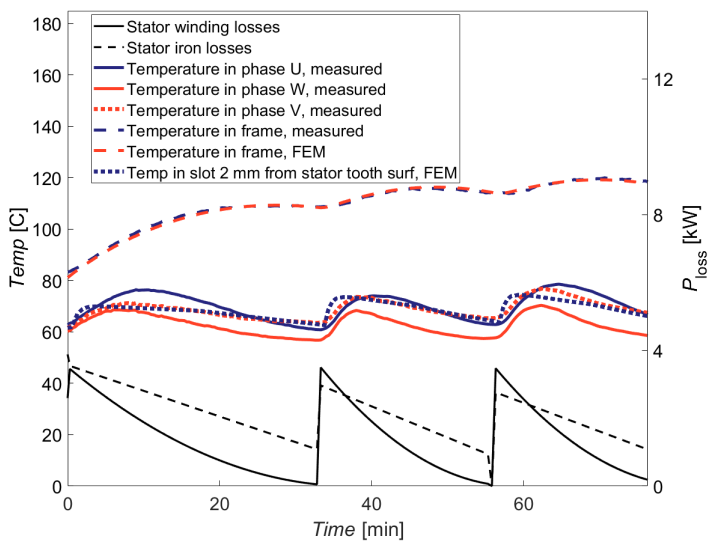

Fig. 15. Measured transient temperature in the slots of three different phases and in the frame, and estimated temperature in the slot winding and the frame applying load variations (different speed and torque values). Water inlet temperature is $50^{\circ} \mathrm{C}$. Water outlet temperature was close to the water inlet temperature along the whole transient (with small variations within $2^{\circ} \mathrm{C}$ ).

rpm, and the torque once again starts from $1300 \mathrm{Nm}$ with a gradual reduction to $150 \mathrm{Nm}$. Finally, when the torque reaches $150 \mathrm{Nm}$, the speed is reduced to $900 \mathrm{rpm}$, and the torque variation is repeated from $1300 \mathrm{Nm}$ with a gradual reduction to $150 \mathrm{Nm}$. The measured and estimated temperature variations under such operations are shown in Fig. 15. The figure shows that the measured frame temperature is very close to the estimated one during the transient. Further, the average measured temperature in the slot windings agrees quite well with the estimated temperature. This verifies the effectiveness of the proposed liquid cooling winding arrangement including the transient conditions because of the relatively short recovery time to cool the winding after high-power load operation.

\section{CONCLUSION}

The isolated nature of the stator slot winding favors a cooling solution that removes heat directly from the stator slot, for instance, the direct winding cooling arrangement (DWLCA). A detailed analysis of the DWLCA cooling capabilities was performed by means of separate measurements 
of the steel tube and the complete coil (having similar dimensions as the actual coil in the machine). The measurement results were combined with a FEM analysis to identify the thermal properties of the proposed winding arrangement. This allowed to fill the gap of unknown parameters of the particular DWLCA applied in the machine and reduce the degree of uncertainty of the overall cooling capabilities of the DWLCA, such as the thermal heat transfer coefficient between the inner tube wall and the circulating water in it (at a water flow of $2 \mathrm{l} / \mathrm{min}$ ) or thermal coupling between the tube outer surface and the copper bundles wrapped around it. These parameters were used to investigate the thermal characteristics in the transient conditions of two similar motors having different cooling arrangements, FLCA and DWLCA. By comparing these two cooling arrangements in the transient condition, it was shown that the DWLCA significantly improves the temperature recovery time in the winding after high-power load operation. The motor with the DWLCA requires much less time (only $1 \mathrm{~min}$ ) to reduce the temperature rise in the winding caused by the high-load operation to half of the total temperature rise, compared with the FLCA, for which this time is $8 \mathrm{~min}$.

The further work related to the DWLCA will focus on the cooling capabilities of this cooling arrangement applying different degrees of tension between the steel tube and the copper strands (wrapped around it), with variation of the water flow speed and temperature. Further, different steel tube sizes and overall winding dimensions will be applied.

\section{REFERENCES}

[1] C. Liu and Z. Lin, "How uncertain is the future of electric vehicle market: Results from monte carlo simulations using a nested logit model," International Journal of Sustainable Transportation, vol. 11, no. 4, pp. 237-247, 2017. [Online]. Available: https://doi.org/10.1080/15568318.2016.1248583

[2] H. Yang, H. Lin, and Z. Q. Zhu, "Recent advances in variable flux memory machines for traction applications: A review," CES Transactions on Electrical Machines and Systems, vol. 2, no. 1, pp. 34-50, March 2018.

[3] X. Zhu, Z. Xiang, L. Quan, W. Wu, and Y. Du, "Multimode optimization design methodology for a flux-controllable stator permanent magnet memory motor considering driving cycles," IEEE Transactions on Industrial Electronics, vol. 65, no. 7, pp. 5353-5366, July 2018.

[4] P. Lindh, M. G. Tehrani, T. Lindh, J. H. Montonen, J. Pyrhönen, J. T. Sopanen, M. Niemelä, Y. Alexandrova, P. Immonen, L. Aarniovuori, and M. Polikarpova, "Multidisciplinary design of a permanent-magnet traction motor for a hybrid bus taking the load cycle into account," IEEE Transactions on Industrial Electronics, vol. 63, no. 6, pp. 3397-3408, June 2016.

[5] K. Grace, S. Galioto, K. Bodla, and A. E. Refaie, "Design and testing of a carbon-fiber-wrapped synchronous reluctance traction motor," IEEE Transactions on Industry Applications, pp. 1-1, 2018.

[6] S. J. Galioto, P. B. Reddy, A. M. EL-Refaie, and J. P. Alexander, "Effect of magnet types on performance of high-speed spoke interior-permanentmagnet machines designed for traction applications," IEEE Transactions on Industry Applications, vol. 51, no. 3, pp. 2148-2160, May 2015.

[7] E. Bostanci, M. Moallem, A. Parsapour, and B. Fahimi, "Opportunities and challenges of switched reluctance motor drives for electric propulsion: A comparative study," IEEE Transactions on Transportation Electrification, vol. 3, no. 1, pp. 58-75, March 2017.

[8] Y. Gai, M. Kimiabeigi, Y. C. Chong, J. Widmer, X. Deng, M. Popescu, J. Goss, D. Staton, and A. Steven, "Cooling of automotive traction motors: Schemes, examples and computation methods- a review," IEEE Transactions on Industrial Electronics, pp. 1-1, 2018.
[9] M. Liu, Y. Li, H. Ding, and B. Sarlioglu, "Thermal management and cooling of windings in electrical machines for electric vehicle and traction application," in 2017 IEEE Transportation Electrification Conference and Expo (ITEC), June 2017, pp. 668-673.

[10] C. Kral, A. Haumer, and T. Bauml, "Thermal model and behavior of a totally-enclosed-water-cooled squirrel-cage induction machine for traction applications," IEEE Transactions on Industrial Electronics, vol. 55, no. 10 , pp. 3555-3565, Oct 2008.

[11] J. Pyrhönen, T. Jokinen, and V. Hrabovcová, Design of Rotating Electrical Machines. New York: John Wiley Sons, 2014.

[12] R. S. Semken, M. Polikarpova, P. Röyttä, J. Alexandrova, J. Pyrhönen, J. Nerg, A. Mikkola, and J. Backman, "Direct-drive permanent magnet generators for high-power wind turbines: benefits and limiting factors," IET Renewable Power Generation, vol. 6, no. 1, pp. 1-8, January 2012.

[13] X. Hu, H. Guo, H. Qian, X. Ding, and Y. Yang, "Development of a highpower-density motor for formula sae electric race car," in IECON 2017 - 43rd Annual Conference of the IEEE Industrial Electronics Society, Oct 2017, pp. 6618-6622.

[14] S. Jumayev, J. J. H. Paulides, K. O. Boynov, J. Pyrhönen, and E. A. Lomonova, "3-d analytical model of helical winding pm machines including rotor eddy currents," IEEE Transactions on Magnetics, vol. 52, no. 5, pp. 1-8, May 2016.

[15] C. Kral, A. Haumer, and S. B. Lee, "A practical thermal model for the estimation of permanent magnet and stator winding temperatures," IEEE Transactions on Power Electronics, vol. 29, no. 1, pp. 455-464, Jan 2014.

[16] M. van der Geest, H. Polinder, J. A. Ferreira, and M. Christmann, "Power density limits and design trends of high-speed permanent magnet synchronous machines," IEEE Transactions on Transportation Electrification, vol. 1, no. 3, pp. 266-276, Oct 2015.

[17] S. Taghavi and P. Pillay, "A sizing methodology of the synchronous reluctance motor for traction applications," IEEE Journal of Emerging and Selected Topics in Power Electronics, vol. 2, no. 2, pp. 329-340, June 2014.

[18] I. Petrov, P. Lindh, M. Niemelä, E. Scherman, and J. Pyrhönen, "High-torque-density ipmsm rotor pole geometry adjustment for smooth torque," IEEE Access, vol. 7, pp. 52 650-52 658, 2019.

[19] P. Lindh, I. Petrov, P. Immonen, J. Pyrhönen, M. Niemelä, J. Anttila, M. Paakkinen, and E. Scherman, "Performance of a direct-liquid-cooled motor in an electric bus under different load cycles," IEEE Access, vol. 7, pp. 86897-86905, 2019.

[20] P. Lindh, I. Petrov, J. Pyrhönen, E. Scherman, M. Niemelä, and P. Immonen, "Direct liquid cooling method verified with a permanent-magnet traction motor in a bus," IEEE Transactions on Industry Applications, vol. 55, no. 4, pp. 4183-4191, July 2019.

[21] P. Lindh, I. Petrov, A. Jaatinen-Värri, A. Grönman, M. MartinezIturralde, M. Satrústegui, and J. Pyrhönen, "Direct liquid cooling method verified with an axial-flux permanent-magnet traction machine prototype," IEEE Transactions on Industrial Electronics, vol. 64, no. 8, pp. 6086-6095, Aug 2017.

[22] P. M. Lindh, I. Petrov, R. S. Semken, M. Niemelä, J. J. Pyrhönen, L. Aarniovuori, T. Vaimann, and A. Kallaste, "Direct liquid cooling in low-power electrical machines: Proof-of-concept," IEEE Transactions on Energy Conversion, vol. 31, no. 4, pp. 1257-1266, Dec 2016.

[23] A. M. EL-Refaie, "Fractional-slot concentrated-windings synchronous permanent magnet machines: Opportunities and challenges," IEEE Transactions on Industrial Electronics, vol. 57, no. 1, pp. 107-121, Jan 2010.

[24] J. Nerg, M. Rilla, and J. Pyrhonen, "Thermal analysis of radial-flux electrical machines with a high power density," IEEE Transactions on Industrial Electronics, vol. 55, no. 10, pp. 3543-3554, Oct 2008.

[25] A. J. G. Yunus A. Cengel, Heat and Mass Transfer: Fundamentals and Applications. Columbus, $\mathrm{OH}$ 43218: McGraw-Hill Education, 2015.

[26] A. Krings, J. Soulard, and O. Wallmark, "Pwm influence on the iron losses and characteristics of a slotless permanent-magnet motor with sife and nife stator cores," IEEE Transactions on Industry Applications, vol. 51, no. 2, pp. 1475-1484, March 2015. 


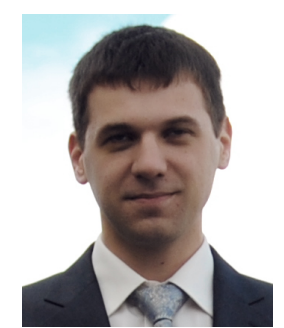

Ilya Petrov received D.Sc. degree in 2015 from Lappeenranta University of Technology (LUT), Finland. $\mathrm{He}$ is currently a researcher in the Department of Electrical Engineering, LUT.

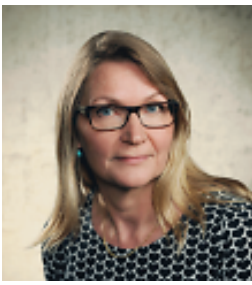

Pia Lindh was born in Helsinki, Finland, in 1969. She received the M.Sc. degree in energy technology and the D.Sc. degree in electrical engineering (technology) from the Lappeenranta University of Technology (LUT), Lappeenranta, Finland, in 1998 and 2004, respectively. She is currently an Associate Professor with the Department of Electrical Engineering, LUT Energy, Lappeenranta, Finland, where she is engaged in teaching and research of electric motors and electric drives.

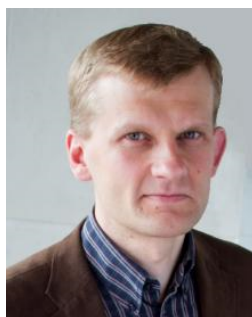

Markku Niemelä received the B.Sc. degree in electrical engineering from Helsinki Institute of Technology, Helsinki, Finland, in 1990 and the M.Sc. and D.Sc. degrees in technology from Lappeenranta University of Technology (LUT), Lappeenranta, Finland, in 1995 and 1999, respectively. He is currently a Senior Researcher with the Carelian Drives and Motor Centre, LUT. His current interests include motion control, control of line converters, and energy efficiency of electric drives.

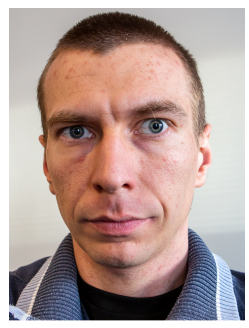

Eero Scherman was born in Lappeenranta in 1987 received the B.Eng. Degree in mechanical engineering from Saimaa University of Applied Science on year 2011. His main interests are development of mechanical engineering in electric motors and generators.

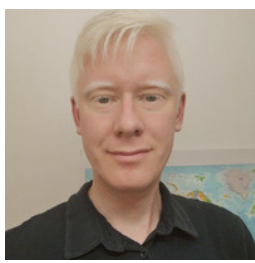

Oskar Wallmark received the Ph.D. degree in electric power engineering from the Chalmers University of Technology, Gothenburg, Sweden, in 2006. He is currently an Associate Professor at the Laboratory of Electrical Energy Conversion (E2C), Royal Institute of Technology (KTH), Stockholm, Sweden. His research interests include control and analysis of electric drives in electric and hybrid electric drive trains.

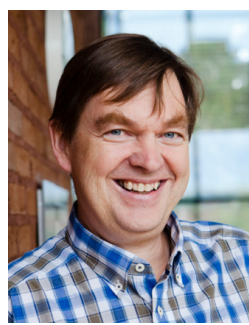

Juha Pyrhönen was born in 1957 in Kuusankoski, Finland, received the Doctor of Science (D.Sc.) degree from Lappeenranta University of Technology (LUT), Finland in 1991. He became an Associate Professor of Electrical Engineering at LUT in 1993 and a Professor of Electrical Machines and Drives in 1997. He is engaged in research and development of electric motors and electric drives. His current interests include different synchronous machines and drives, induction motors and drives and solid-rotor high-speed induction machines and drives. 